\title{
A cafeicultura familiar e um possível modelo para o desenvolvimento do turismo do café em Minas Gerais
}

\author{
The familiar coffee culture: a possible inspiration for the coffee tourism \\ development in Minas Gerais State, Brazil
}

\author{
Helga Cristina Carvalho Andrade, Marina Carneiro Bernardes Moss
}

\begin{abstract}
RESUMO
A cafeicultura brasileira é composta $60 \%$ por agricultores familiares, responsáveis por $25 \%$ da produção nacional. No estado de Minas Gerais, a cafeicultura exerce grande influência sobre muitas economias locais, cujos municípios em geral estão localizados em áreas de montanha. O café, no contexto da agricultura familiar, não pode ser tratado com um produto genérico, já que em torno do mesmo formou-se uma cultura que ultrapassa o modo produtivo, influenciando a vida em comunidade, as tradições e mesmo a qualidade do produto final. Por ser um produto influenciado pelo microclima e pelo fator humano, o café goza de prestígio como gênero gastronômico, e o universo que o envolve pode atrair fluxo turístico para as regiões produtoras. Na Colômbia, características locais - grande maioria de agricultores familiares, dificuldades de cultivo em larga escala e de comercialização - levaram à criação da Federação dos Cafeicultores da Colômbia, organismo que não só buscou a valorização do café colombiano perante o mercado internacional, como promoveu nas origens condições para o desenvolvimento turístico centrado no tripé produto (café) $x$ produtor (cafeicultor) $\mathrm{x}$ meio produtivo (microclima). Os objetivos desse trabalho consistem em i) identificar as características semelhantes entre as realidades colombiana e mineira quanto à cultura do café; ii) analisar o modelo de aproveitamento turístico do café na Colômbia; e iii) apontar diretrizes para o turismo rural focado na cafeicultura familiar mineira. A metodologia incluiu três etapas de trabalho, sendo a primeira de revisão bibliográfica, a segunda de investigação documental sobre o objeto de estudo e a terceira uma visita ao Eixo Cafeeiro, para vivenciar uma experiência de turismo rural na Colômbia. Os resultados encontrados mostram que o caso de sucesso na Colômbia, que possui características geográficas e culturais semelhantes ao estado de Minas Gerais com relação ao café, apresenta-se como um modelo a ser analisado e adaptado, visando à valorização do café mineiro em suas especificidades, o incremento de renda do cafeicultor familiar e a criação de uma identidade gastronômica mineira que inclua o café.
\end{abstract}

PALAVRAS-CHAVE: Cafeicultura Familiar; Turismo do Café na Colômbia, Minas Gerais; Turismo Rural na Agricultura Familiar. 


\section{ABSTRACT}

The coffee culture in Brazil is formed $60 \%$ by familiar farmers, responsible for $25 \%$ of the national production. In Minas Gerais state, the coffee culture has large influence over many local economies, in which municipalities generally are located into mountain areas. The coffee, into the familiar production context, can not be treated as a generic product, as well as around it has been formed a culture which go across the production way, influencing the life in community, the tradition and even the coffee quality. Because of it is a product influenced by de terroir and by the human factor, coffee enjoys status as gastronomic stuff, and its universe can attract touristic outflow to the producer regions. The colombian local characteristics - large quantity of familiar farmers, difficulties of producing in large scale and commercializing - conduced them to the creation of the Federación de Cafeteros de Colombia, organism which not just worked for the best coffee price on the international market, but promoted on the origins conditions to touristic development based on the three basis product (coffee), producer (coffee farmers) and producer place (terroir). The objectives of this article are i) identify the similar characteristics between colombian and mineira realities, related to coffee; ii) analyze the colombian model of touristic exploitation of coffee; and iii) appoint directions to the rural tourism focused on familiar coffee culture of Minas Gerais. The methods to reach the objectivies includes three fases: the first was a bibliografic review, the second was a documental investigation of the place studied and the third a touristical visitation to the Eje Cafetero, in order to live na experience of rural tourism in Colombia. The success case into a country which has so many characteristics in common with Minas Gerais state in coffee subjects, presents as a model to be analyzed and adapted, in order to provide value to mineiro coffee, increasing the familiar farmers' incomes and creating an gastronomic identity to Minas Gerais, including the coffee product.

KEYWORDS: Familiar Coffee Culture; Coffee Tourism in Colombia, Minas Gerais; Rural Tourism Into Familiar Agriculture.

\section{Introdução}

Segundo dados do Pronaf - Programa Nacional de Fortalecimento da Agricultura Familiar, citados por Coelho (2005) e Pedrini (2005), a cafeicultura brasileira é composta por $75 \%$ de pequenos produtores, dentre os quais $60 \%$ são agricultores familiares, com área de até 5 hectares. Esse segmento responde por $25 \%$ da produção do gênero no país. A cafeicultura familiar produziu aproximadamente 10 milhões de sacas em 2005, contribuindo com $R$ \$2,5 bilhões para o PIB agrícola e empregando cerca de 1,8 milhão de pessoas por ano. O café é um produto historicamente estratégico para as exportações brasileiras, figurando como segundo principal produto da agricultura familiar. No caso do café arábica, cujo maior produtor é o estado de Minas Gerais, conta com 193.328 estabelecimentos, contra 48.309 estabelecimentos não-familiares (IBGE, 2006). O Brasil permanece, por sua vez, como principal produtor mundial de café e segundo maior consumidor. 
Entretanto, segundo Coelho (2005), apesar da grande diversidade nas formas sociais de produção, a maioria dos estudos não leva em conta critérios importantes, sob pena de confundir os termos 'agricultor familiar' e 'pequeno agricultor', conceitos distintos que se referem, respectivamente, a um modo de produção e ao porte de uma propriedade produtiva.

A Agricultura Familiar é definida pela Lei 11326, de 24 de julho de 2006, como aquela que realiza atividades no meio rural, atendendo, simultaneamente, aos seguintes requisitos:

I - não detenha a qualquer título, área maior do que quatro módulos fiscais;

II - utilize predominantemente mão-de-obra da própria família nas atividades econômicas do seu estabelecimento ou empreendimento;

III - tenha percentual mínimo da renda familiar originada de atividades econômicas do seu estabelecimento ou empreendimento, na forma definida pelo Poder executivo (redação dada pela Lei $n$ 12.512, de 2011);

IV - dirija seu próprio estabelecimento ou empreendimento com sua família (BRASIL, 2006)

O café, no contexto da agricultura familiar, não pode ser tratado como um produto genérico, apenas uma commodity, como foi tratado por um longo período. Deve ser reconhecido como uma cultura, a cafeicultura, cujo resultado produtivo - o café in natura depende de uma série de opções feitas pelo cafeicultor ao longo da cadeia produtiva, como tamanho da propriedade, condições ofertadas pelo microclima natural, tratamento do solo, disponibilidade de recursos, relações de trabalho e produção, maquinário e cuidados na colheita e pós-colheita, benefício, tipo de mercado acessado e comercialização, além do trabalho humano (STOLCKE, 1986, apud COELHO, 2005). Quando um trabalhador é retirado do processo, não se trata de uma simples reposição de um fator de produção, como acontece na cafeicultura patronal. Existem outros valores que circundam esse serfator de produção, que não podem ser tratados separadamente: a cafeicultura familiar é um sistema altamente influenciável por cada componente.

No estado de Minas Gerais, a cafeicultura exerce grande influência na economia de vários municípios produtores, que dependem diretamente da atividade. A participação da família nas atividades relacionadas à cultura é essencial nas regiões produtoras do estado, em especial na cafeicultura de montanha no Sul do estado e na Zona da Mata (Figura 1), determinando uma grande oferta de empregos e contribuindo para aliviar as pressões sociais estimuladas pelo êxodo rural (COELHO, 2005). Segundo estudos realizados pelo INAES em 2010, a área destinada à cafeicultura e a produtividade nessa área cresceram, aproximadamente, 30\% entre os anos de 1996 e 2010, totalizando quatorze anos de intervalo (CORDEIRO, 2010). 


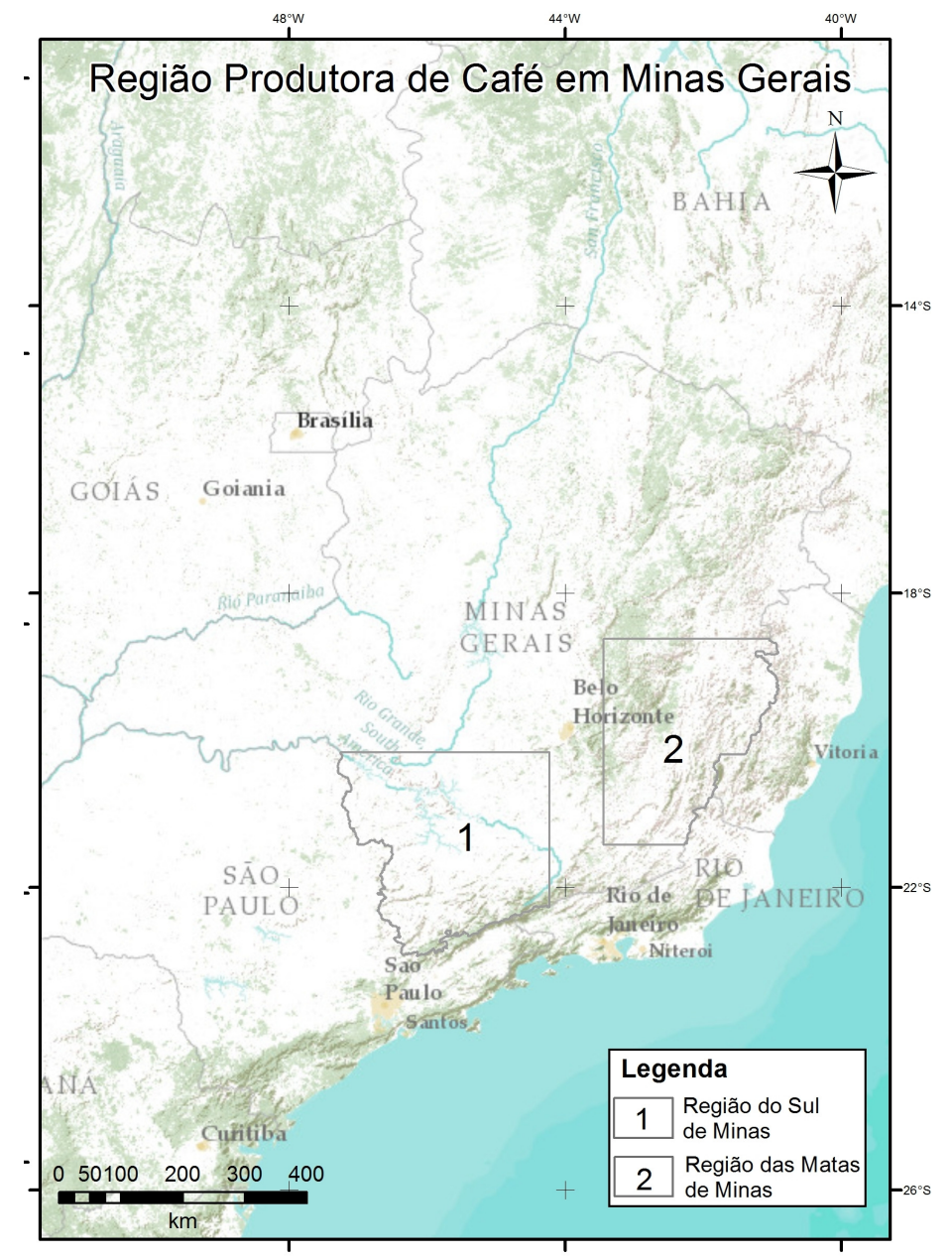

Figura 1: Regiões produtoras de café em Minas Gerais. Fonte: autoria própria.

Figure 1: Coffee producing region in Minas Gerais. Source: authors.

Pedini (2005) comenta que as condições topográficas onde a maioria desses cafeicultores familiares se encontra, aliadas à baixa produção, pressão fundiária para as regiões de montanha, pouca ou nenhuma capacidade de mecanização dos processos produtivos e falta de acesso a mercados, faz com que a cafeicultura familiar esteja em desvantagem no cenário nacional, quando comparada às produções fundiárias, altamente vinculadas às estruturas de comercialização.

Como o café é uma cultura sazonal no uso do trabalho, ou seja, na colheita e em alguns tratos culturais demanda-se maior mão-de-obra, e nos demais períodos essa mãode-obra fica ociosa, é compreensível a existência da pluriatividade entre os cafeicultores familiares. Para não correr o risco de classificar mal ao traçar um perfil para o cafeicultor familiar, Coelho (2005) ressalta que uma reflexão sobre o trabalho familiar como princípio gerador de valor econômico é mais importante que levantamentos sobre produção ou preço do produto. 
Pedini (2005) ressalta que a adoção de métodos produtivos para mercados específicos, como o orgânico, e formas de organização observando a responsabilidade ambiental e social, como o exigido na certificação fair trade (comércio solidário), constituem saídas inteligentes para que o agricultor familiar alcance o mercado com uma valorização mais justa, com ou sem o apoio de políticas públicas, eliminando ou reduzindo os intermediários no processo de comercialização do café.

\section{Café e Turismo}

O café é um produto de microclima. Isso significa que as características de cada região onde é produzido, bem como seu componente humano, determinam diferenças cruciais na bebida produzida por determinados grãos. Conforme relata Andrade (2010), a apreciação do café seguiu o mesmo caminho que trilhou o vinho: de produto de importância econômica inegável, o café se tornou um produto de luxo e sinônimo de fruição, de prazer. Esse prazer, por sua vez, é cada vez mais adotado como uma prática de lazer e também de luxo e refinamento. As novas tendências de consumo atuais, que claramente privilegiam o consumo objetivando uma experiência e um valor simbólico, abandonam o valor estritamente comercial de produtos como o café, apontando o turismo e a gastronomia como práticas muito recorrentes e valorizadas na contemporaneidade (ANDRADE, 2010).

Paralelamente a esta valorização gastronômica que tem colocado o café em evidência, a bebida pode ser considerada um ícone da cultura mineira, associado por excelência ao contato social e à boa hospitalidade. Torres (2010) ressalta que o universo simbólico do café envolve uma variedade de conhecimentos e práticas que fortalecem a cultura regional, e mesmo uma mineiridade, identidade complexa atribuída a Minas Gerais e que remonta ao ser mineiro, com seus hábitos, história e principalmente alimentação. Essa mineiridade, como personificação da cultura mineira, consiste no mais rico atrativo de caráter turístico do Estado, na medida em que o patrimônio imaterial apresenta relações as mais diversas possíveis entre o alóctone (o visitante) e o autóctone (o visitado).

Andrade (2010) observa, ainda, que provar uma fruta no pé, uma quitanda à beira do forno, uma cachaça no alambique, assim como beber um café de coador debruçado à janela que dá vistas à lavoura, carregam significados essenciais para a construção da experiência turística. A comida e a bebida consumidos dentro do seu microclima, preparados por gente do meio produtivo e que celebra laços verdadeiros com aquela terra teriam, assim, um maior sentido de legitimidade. Dessa forma, entende-se que a culinária regional passa a servir de mote principal para o deslocamento turístico em muitos casos, e o café retrata oportunamente essa impressão, somado às quitandas, ao pão-de-queijo e a outros itens da culinária mineira.

Segundo Schluter (2003), a degustação de alimentos e bebidas típicas no seu local de produção possibilita a interação do visitante com a cultura local, evidenciando a importância cada vez maior que a gastronomia está assumindo para o turismo. Atendendo a essa nova necessidade criada, que conjuga a curiosidade sobre a produção alimentar e o desejo de consumir gêneros em sua atmosfera de origem, são criadas rotas gastronômicas em todo o mundo, organizadas em função de um produto ou traço cultural ca- 
racterístico. Muitas vezes, a motivação principal para o desenvolvimento dessas rotas é incentivar o consumo de produtos que existem em abundância no destino turístico ou valorizar produtos dos quais as comunidades locais dependam fortemente, promovendo, assim, o maior preço do produto frente a mercados globais e o desenvolvimento de áreas rurais.

Sob este entendimento, a implementação do turismo rural em empreendimentos de agricultura familiar apresenta-se com grande potencial, contribuindo para a consolidação dos diferenciais de um produto frente aos seus concorrentes em outras localidades. Associado ao fluxo turístico atraído para regiões produtoras, as certificações e indicações geográficas podem elevar um núcleo produtivo à excelência e unicidade. Para fins metodológicos, entender-se-á o Turismo Rural na Agricultura Familiar conforme as orientações básicas para o turismo rural, determinados pelo Ministério do Turismo:

É a atividade turística que ocorre no âmbito da unidade de produção dos agricultores familiares que mantêm as atividades econômicas típicas da agricultura familiar, dispostos a valorizar, respeitar e compartiIhar seu modo de vida, o patrimônio cultural e natural, ofertando produtos e serviços de qualidade e proporcionando bem estar aos envolvidos. (BRASIL, 2010).

\section{Justificativa e Objetivo}

Frente à já destacada importância do café na economia do estado de Minas Gerais, torna-se necessário desenvolver mecanismos que garantam a sustentabilidade do agronegócio café nas regiões que dele dependem. O café também é de inegável importância para a manutenção das tradições regionais. Seu cultivo e seu consumo se apresentam como um verdadeiro patrimônio rural, gastronômico e turístico a ser explorado com vistas ao desenvolvimento das comunidades cafeicultoras.

Apesar de ser a maior região produtora, localizada no maior país produtor e segundo maior consumidor mundial, Minas Gerais vem desenvolvendo sua identidade turística sem dar ao produto café o devido lugar de destaque, talvez pela opulência de nossas mesas, que permite diversas memórias no que toca à alimentação. Entretanto, a Colômbia, país com condições semelhantes às do nosso Estado, tomou a frente e transportou para o turismo o universo da cafeicultura, tornando-se conhecida como produtora dos melhores cafés do mundo. Há, portanto, que se investigar a trajetória que levou o país a transformar suas limitações em vantagem competitiva, refletindo sobre o aprendizado que pode ser gerado a partir da experiência colombiana, na construção de um destino sólido para o turismo do café em Minas Gerais.

Assim, propõem-se, como objetivos deste trabalho:

- Identificar as características semelhantes entre as realidades colombiana e mineira quanto à cultura do café;

- Analisar o modelo de aproveitamento turístico do café na Colômbia;

- Apontar diretrizes para o turismo rural focado na cafeicultura familiar mineira. 


\section{Metodologia}

A metodologia utilizada neste trabalho inclui três etapas:

i) Reunião de instrumental teórico a partir da leitura de censos, artigos, livros, dissertações e teses disponibilizadas em publicações técnicas, sites e bancos de teses das universidades na internet.

ii) Pesquisa exploratória sobre o objeto de estudo, por meio de informações oficiais e outras publicações de importância para o seu delineamento;

iii) Realização de viagem ao Eixo Cafeeiro colombiano, nos dia 6 a 8 de junho de 2011, a fim de vivenciar a experiência do turismo rural em uma unidade produtora de café tradicional.

\section{Colômbia: Café, Cafeicultor e Região Produtora}

Com as primeiras plantações comerciais datadas do final do século XVIII, a produção colombiana desde o século XIX assentou-se nas pequenas propriedades. As constantes quedas e instabilidade na valorização do produto no mercado internacional, somado às crises internas vividas pelo país, desestimulou a manutenção de grandes fazendas.

Nem sempre o país, cuja economia depende tão fortemente do café, gozou de um lugar entre os maiores produtores mundiais. No início do século XX, a Colômbia respondia por apenas $3 \%$ das exportações mundiais de café (FLEURY, 2008), e atualmente figura na terceira posição entre os maiores exportadores do mundo (SCHOLER, 2006)

Existem, na Colômbia, mais de 563 mil famílias produtoras de café, distribuídas em 588 municípios em 20 departamentos. Destas, $96 \%$ é formado por famílias campesinas que possuem áreas menores a 5 hectares cultivados, e são responsáveis por $70 \%$ da produção nacional (FEDERACIÓN..., 2012). Essa condição dada pela fragmentação da posse de terras, somada à economia de subsistência e baixo nivel educativo, frequentes na agricultura familiar latinoamericana, faz com que essas famílias sejam extremamente vulneráveis às mudanças ocorridas no entorno, e a única forma de garantir que os benefícios atinjam os grupos que mais deles necessitam, é a união em instituições representativas sólidas.

Desde o início do século XX, os grandes desafios da geografia montanhosa e os pequenos volumes de produção individuais motivaram os cafeicultores colombianos a se unirem para solucionar problemas comuns de logística e comercialização. Essa necessidade de desenvolver ações e políticas de benefício comum gerou condições para a criação da Federación de los Cafeteros de Colombia, em 1927. A Federação de Cafeicultores foi decisiva para que um movimento de defesa ao cafeicultor familiar colombiano surgisse, revelando a vulnerabilidade desse produtor e exigindo das políticas e do mercado um posicionamento que permitisse negócios mais igualitários e justos, o que resultou em uma filosofia de comercialização de impacto positivo para as famílias produtoras. Atualmente, a Federação afirma oferecer uma rede de 541 pontos de compra em todas as regiões produtoras, através de cooperativas. Dessa forma, os pequenos produtores sempre têm a possibilidade de comercializar seu café com a Federação, ou diretamente a outros com- 
pradores, em um processo de decisão julgado autônomo e transparente.

A principal política de comercialização, conhecida como 'garantia de compra', gera um preço mínimo de transação para o café em todas as origens colombianas, nas quais os compradores do mercado, como corretoras e outros intermediários privados, devem oferecer preços similares ou superiores ao preço mínimo estipulado. A Federação comercializa cerca de $30 \%$ da produção colombiana, constituindo, assim, um dos maiores exportadores individuais de café do mundo, o que oferece uma solução ao desafio da exportação devido aos pequenos volumes produzidos individualmente. Além disso, essa política gera, como consequência, um impacto positivo sobre os preços dos $70 \%$ restantes da colheita, comercializados diretamente pelos produtores. Dessa forma, a Federação busca garantir a remuneração justa ao produtor, por meio do maior preço pago pelo produto.

Somado aos esforços da comercialização, outra mudança que consagrou ao café colombiano sua fama mundial foi a atenção massiva à qualidade no processo produtivo. Desde o princípio da atuação da Federação, unidades móveis de extensão rural percorreram os municípios produtores para disseminar técnicas avançadas de cultivo, benefício e comercialização do café. Antes da metade do século XX, a Colômbia já contava com sistemas de classificação e certificação (ANDRADE, 2010). Não é difícil entender por que, em pouco tempo, o café colombiano seria conhecido como o melhor café do mundo.

A Colômbia possui especificidades climáticas devido à sua localização próxima à Linha do Equador e grande parte de seu território dividido entre a Cordilheira dos Andes e a Floresta Amazônica. Por isso, o país possui um regime de chuvas que se distribui quase regularmente durante todo o ano (CAFÉ..., 2012). Tal característica resulta em uma dificuldade para a cafeicultura, pois é importante efetuar a colheita no momento em que a maioria desses frutos se encontram no ponto ideal de maturação (DONZELES et al.,2008). A Colômbia, por seu regime de chuvas, apresenta diversas floradas, e portanto é possível encontrar, no cafeeiro, uma distribuição de frutos em diferentes etapas de maturação. Caso a colheita fosse feita de forma mecanizada, ou se a colheita manual fosse realizada por derriça ${ }^{1}$, a perda de café reduziria ainda mais o volume de colheita, tornando a cultura inviável. O relevo montanhoso também impede essa mecanização, e por isso a colheita é feita seletivamente, fruto por fruto. Para compensar essa dificuldade, o fato foi usado como estratégia de valorização do café, que por ser "selecionado", seria de melhor qualidade. $\mathrm{E}$, de fato, apesar de diversos estudos confirmarem que a colheita seletiva em qualquer região produtora resulta em melhores cafés, na Colômbia isso foi usado como estratégia de comercialização, que tornou a dificuldade uma vantagem competitiva frente aos concorrentes.

O cultivo do café na Colômbia é uma herança da colonização antioquenha, e deixou como legado um conjunto de tradições e manifestações culturais, entre as quais podem ser destacadas as festas nacionais do café e da colheita; o artesanato, em que sobressaem motivos relacionados ao café e também produtos comestíveis como conservas, bolo de rolo, pamonha, rapadura e outros derivados de cana; gastronomia representada pelas comidas de montanha, características por sua quantidade, modo de preparo, apresentação, cores e estética; a presença da mula, principal veículo de carga; e o vestuário típico com uso do chapéu, poncho, manta e embornal (PAISAJE...,2012).

Observa-se que os pilares da consagração da Colômbia como reduto do melhor 
café do mundo consiste em um tripé. O primeiro fator, a qualidade do seu café, funcionou como argumento irrefutável para o mercado externo. O segundo fator, o cafeicultor familiar colombiano, foi representado pela figura de Juan Valdéz, personagem criado em 1981 com feições, vestimenta e comportamentos típicos do verdadeiro cafeicultor colombiano tradicional. Os Estados Unidos, provavelmente pelo interesse em incentivar a produção de café na Colômbia, substituindo o cultivo da coca e, com isso, reduzindo o interesse dos locais no tráfico de cocaína, foi um grande disseminador da marca Juan Valdéz. Ao criar a marca do cafeicultor tradicional, a Federação mostrava aos compradores internacionais que seu café era produzido valorizando e preservando as tradições rurais, remunerando o produtor de forma justa e permitindo-lhe qualidade de vida a partir da renda do café. Isso era tudo o que os mercados contemporâneos nos Estados Unidos e Europa precisavam ouvir, em resposta à exigência latente de qualidade associada à responsabilidade social.

O terceiro fator do tripé consiste no microclima. Conforme mencionado por ANDRADE (2010), as condições ambientais, associadas ao fator humano, tornam cada café exclusivo. Diversos estudos apontam que o café produzido em grandes altitudes possui qualidade diferenciada, e associada ao método de beneficiamento do grão, por via úmida ${ }^{2}$, o produto resultante é um café chamado de suave, de características diferentes dos cafés naturais ${ }^{3}$ tipicamente produzidos no Brasil. Ao afirmar que sua terra é única, o cafeicultor colombiano convida o comprador e também o consumidor final a comprová-lo, visitando as regiões produtoras colombianas.

Além das condições propícias para um café de excelente bebida, a localização do país faz com que as áreas produtivas se desenvolvam em diferentes paisagens naturais e culturais. Por essa razão, as regiões produtoras colombianas formam uma das redes sociais de maior diversidade de culturas, incluindo comunidades indígenas, afrodescendentes e descentes de colonos, com manifestações culturais facilmente diferenciáveis

entre

as regiões, "aportando sua maravilhosa idiossincrasia à grande família de cafeicultores colombianos" (FEDERACIÓN..., 2012).

\section{O Eixo Cafeeiro e a Experiência do Turismo Rural}

O Eixo Cafeeiro é um sistema que se desenvolveu em torno de três cidades centrais: Manizales, Pereira e Armenia. Por esse motivo, é também conhecido como Triângulo do Café. Cada uma das cidades pertencentes a esse sistema possui forte personalidade histórica e elementos urbanos. Esse território, de acordo com Arango (2005), integra municípios com intensas relações históricas, culturais e políticas, com influência econômica recíproca e em cujos territórios vem sendo desenvolvidos projetos de integração entre o urbano e o rural, notavelmente pela influência da produção e comercialização do café. Devido à sua forte integração, o Eixo Cafeeiro é definido por Arango (2005) como uma cidade-região, termo que pretende caracterizar um aglomerado policêntrico de cidades marcado pelo desenvolvimento territorial equilibrado e equitativo.

O Eixo Cafeeiro se localiza no cruzamento de dois importantes corredores de acessibilidade e atividade urbana do país: o corredor de cidades que se estende de Ipiales 
ao Valle de Aburrá e o corredor que se desloca de Sogamoso a Buenaventura, passando pela capital nacional Bogotá (Figura 2). Também se situa no centro do triângulo formado por Bogotá, Medellín e Cali, três das mais importantes cidades do país. Apesar da localização de alto valor geoestratégico, essa rede de cidades é considerada território de passagem, pois existe a percepção que seus centros urbanos mais importantes ainda não cumprem seu papel de articuladores (ARANGO, 2005).

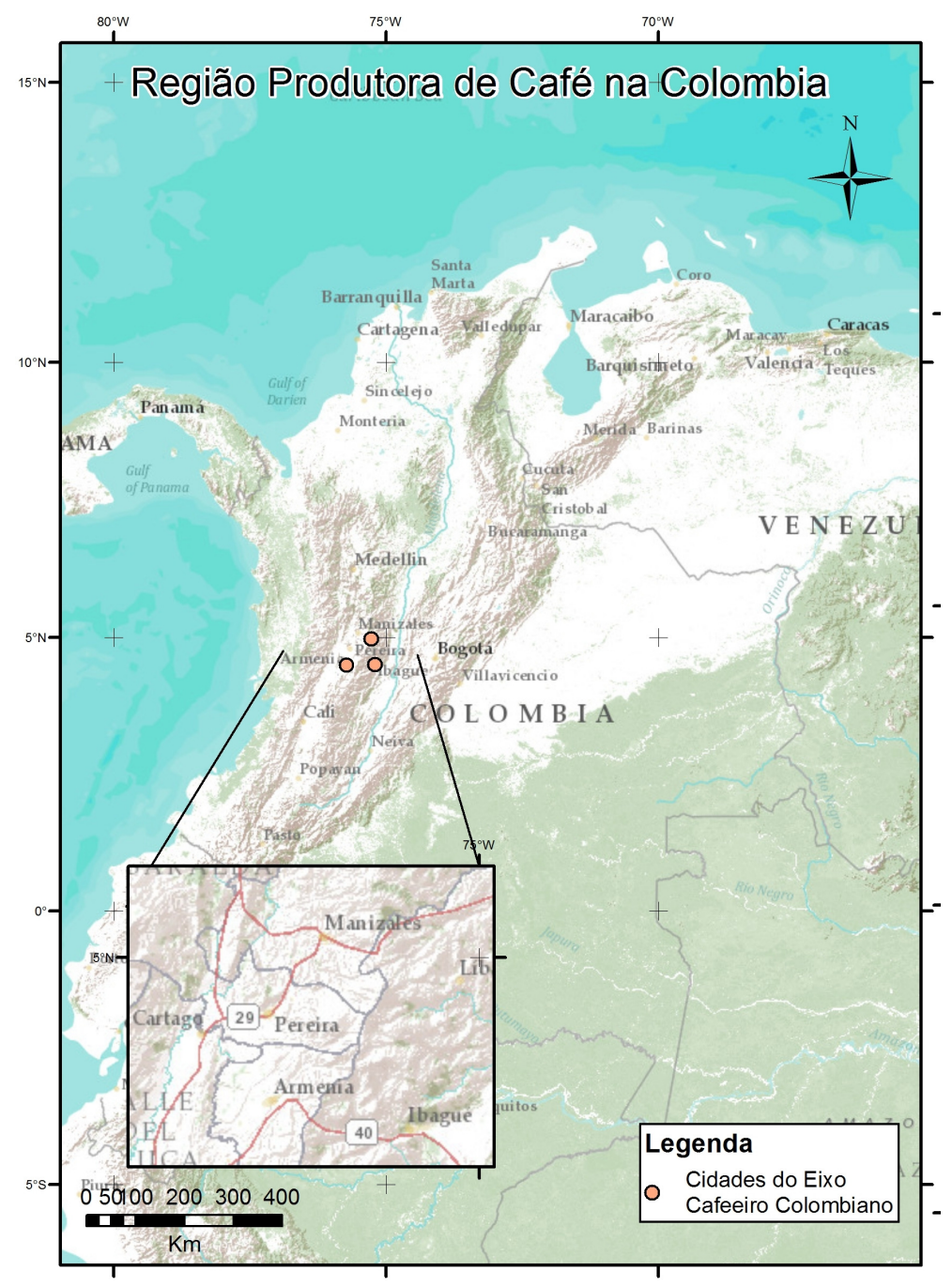

Figura 2: Mapa do eixo cafeeiro colombiano. Fonte: autoria própria. Figure 2: Coffee producing region in Colombia. Source: authors.

Instituído pelo governo colombiano como uma das zonas turísticas do país, o Eixo Cafeeiro figura como principal elemento da chamada paisagem cultural cafeeira, com 24 mil propriedades produtoras de café, onde cerca de 80 mil pessoas se dedicam à cultura (PAISAJE..., 2012). Essa paisagem cafeeira pleiteia seu reconhecimento perante 
a Unesco como Patrimônio Cultural da Humanidade. As propriedades se localizam em média a 1500 metros de altitude, e a paisagem é viva e mutante, revelando em cada curva da estrada sobre os Andes belos cenários panorâmicos. O Cenicafé, principal referência científica para a cultura do café no país, desenvolve projetos visando o equilíbrio entre as tradições e a inovação, recomendando o plantio da variedade castillo, de origem local e cultivada exclusivamente na Colômbia.

A visita de campo ao Triângulo do Café confirmou que o destino encontra-se bem estruturado. De acordo com as informações divulgadas pelo portal oficial de turismo da Colômbia, o Eixo Cafeeiro se consolidou como o primeiro destino rural da América Latina, graças a suas fazendas tradicionais adaptadas em alojamentos turísticos de alto nivel. A experiência em Armenia ${ }^{4}$, onde foi alojado em um hotel rural um grupo de sete visitantes brasileiros consumidores ou envolvidos profissionalmente com o café, comprovou o fato de que lá é possível gozar de excelentes instalações (quartos duplos em chalés, finamente decorados e perfumados, com mobiliário tradicional e ambiente aconchegante) e serviços (todas as refeições postas em uma área de restauração tradicional, com rica montagem dos pratos, preparados com ingredientes típicos). O hotel localiza-se em uma fazenda produtiva, na qual é possível observar as lavouras e uma paisagem belíssima de montanha. Como a visita se realizou em junho, época de baixa produção no país, não foi possível acompanhar a colheita nessa propriedade.

Para vivenciar a cadeia produtiva do café colombiano, o grupo foi conduzido a uma área chamada de Vereda Callelarga, pertencente ao município de Calarcá, e situada a 20 minutos de Armenia, por estrada pavimentada. Nesse local, existe um modelo de negócio denominado, em idioma castelhano, Recuca - Recorrido de la Cultura Cafetera. O Recuca consiste em uma propriedade produtiva preservada, totalmente adaptada para a recepção de turistas, possuindo inclusive uma faixa da área produtiva destinada à visitação. Em pequenos circuitos de duração média de 3 a 4 horas, incluindo almoço ou pequenas refeições (semelhantes ao nosso "café da tarde mineiro"), os visitantes são guiados por um dos funcionários do local por toda a cadeia produtiva. $O$ atendimento é feito somente em espanhol, mas é permitido o acompanhamento de guias particulares. Apesar de uma certa barreira lingüística, que entre português e espanhol nem é tão significativa, o trabaIhador que acompanha o grupo percorre todas as áreas da propriedade, demonstrando os processos detalhadamente e sanando dúvidas dos visitantes a respeito do plantio, manejo das plantas, solo, clima e colheita.

Depois de percorrer todas as etapas, os visitantes são convidados a se vestirem como cafeicultores tradicionais. Todos se dirigem ao trecho reservado da lavoura e são orientados a catar os grãos maduros de café, colocando-os no cesto. Uma pequena competição de quem colhe mais café é estimulada. Uma das visitantes recebe uma espécie de recipiente térmico, e o guia colombiano lhe ensina as palavras que deve gritar para chamar os colhedores de café para o descanso, servindo-lhes a tradicional agua-depanela, uma preparação gelada de água, rapadura e limão, geralmente levada ao campo nos períodos de calor.

Depois de descansados, os "cafeicultores por um dia" entregar ao "feitor" sua parcela colhida, recebendo em troca uma nota de valor simbólico, da mesma moeda com a 
qual eram pagos os colhedores no princípio do século XX. Em seguida todos observam e executam tarefas como o descascamento e secagem dos grãos à moda antiga, conhecem a torra e a moagem e são convidados a sentar-se em uma pequena cozinha, semeIhante às cozinhas de fogão à lenha mineiras, onde é servido um café coado no coador de pano, em canecas esmaltadas, acompanhado de quitutes que também se assemeIham à culinária mineira, como os buñuelos (bolinhos fritos de queijo).

O tratamento pessoal e mesmo fraternal com que o grupo é tratado durante as atividades impressiona. Amantes do café convidados a participar dessa experiência, todos deixaram o local ainda mais envolvidos pelo universo do café. No Recuca, informou-se que é comum o fluxo de turismo interno e regional, em que moradores de grandes cidades se dirigem ao interior em busca de novas experiências e de um retorno às raízes, e também fluxo de escolas e grupos infanto-juvenis, que caracteriza um turismo pedagógico (Recuca...,2012)

Um fato que impressiona é que, apesar do deslocamento aéreo do Brasil para a Colômbia ser custoso, no Eixo Cafeeiro, hospedagem, alimentação e atividades possuem um alto valor agregado e custo relativamente baixo, mesmo se considerado o custo de vida do país. Portanto, o turismo rural na região produtora de café apresenta-se largamente acessível para a população de classe média colombiana.

\section{Discussão: um possível modelo para Minas Gerais?}

Podemos, a partir dos dados investigados, traçar o perfil comparativo entre as realidades colombiana e mineira, baseado no tripé produto $\mathrm{x}$ produtor $\mathrm{x}$ meio produtivo, no qual se sustenta a lógica colombiana (Tabela 1).

Observa-se, com isso, que o estado de Minas Gerais goza de características muito semelhantes à Colômbia, em especial no que toca à cultura do café. A maioria das condições ambientais são semelhantes, quando se considera a cafeicultura de montanha em Minas Gerais, e a maior região produtora do país, que é o Sul de Minas. Por constituir uma região farta em recursos hídricos, vegetais e animais, o Sul de Minas é uma região que recebe um considerável fluxo turístico. Entretanto, são mínimas as iniciativas que oferecem produtos envolvendo a agricultura familiar, especialmente a cafeicultura. Apesar da importância econômica e cultural do gênero para o estado, a identidade gastronômica e turística de Minas tem sido construída pautada em produtos como a cachaça, o pão-dequeijo e o frango com quiabo, sem destinar a devida atenção ao produto café. Tal fato foi comprovado durante o evento Salão Mineiro do Turismo, promovido em Belo Horizonte nos dias 18 e 19 de maio de 2012: durante o debate com o tema "Gastronomia mineira patrimônio do mundo", que incluiu representantes do SENAC e da Associação Brasileira de Gastronomia e Cultura, em nenhum momento foi sequer citado o café com parte do patrimônio gastronômico mineiro. No Panorama do Turismo Rural na Agricultura Familiar, documento publicado pelo Ministério do Turismo, a epígrafe da seção que trata do estado de Minas Gerais é "Café, leite e cultura - mineirice em toda parte", e há menção ao Circuito Turístico das Montanhas Cafeeiras, que abrange as cidades de São Sebastião do Paraíso, Guaxupé, Guaranésia, Juruaia e Muzambinho. (BRASIL, 2007). Entretanto, nem mesmo nas cidades citadas tem-se conhecimento de um produto turístico que ofereça atividades envolvendo a produção do café. 
Tabela 1: perfil comparativo entre a cafeicultura colombiana e de Minas Gerais. fonte: autoria própria. Table 1: a compared profile between Colombia \& Minas Gerais' coffee culture. Source: authors.

\begin{tabular}{|c|c|c|}
\hline & Colômbia & Minas Gerais \\
\hline Produto & $\begin{array}{l}\text { Colheita seletiva; café descas- } \\
\text { cado }\end{array}$ & $\begin{array}{l}\text { Colheita semimecanizada; predomínio } \\
\text { de café natural, porém volume consi- } \\
\text { derável de café descascado. }\end{array}$ \\
\hline Produtor & $\begin{array}{l}\text {-96\% cafeicultores familiares, } \\
\text { (menos de } 5 \text { ha), produzindo } \\
70 \% \text { do total nacional; } \\
\text { •Baixo nivel educacional, eco- } \\
\text { nomia de subsistência, vulne- } \\
\text { rabilidade ao entorno; } \\
\text {-Organização em uma federa- } \\
\text { ção única, que determina } \\
\text { preços mínimos, independên- } \\
\text { cia na comercialização; } \\
\text {-Cultura não sazonal no uso } \\
\text { do trabalho (colheita distribuí- } \\
\text { da ao longo do ano) } \\
\text { •Cultura específica vinculada } \\
\text { à produção do café; } \\
\text {-Sobreposição da vida urbana } \\
\text { e rural. }\end{array}$ & $\begin{array}{l}\text {-60\% cafeicultores familiares (menos } \\
\text { de } 5 \text { ha), produzindo } 25 \% \text { do total } \\
\text { (dados nacionais); } \\
\text {-Médio nivel educacional, pluriativida- } \\
\text { de, alta dependência do café; } \\
\text {-Organização em cooperativas que } \\
\text { trabalham em geral de forma isolada, } \\
\text { inexistência de preços mínimos, rela- } \\
\text { tiva dependência na comercialização; } \\
\text {-Cultura sazonal no uso do trabalho } \\
\text { (concentração na colheita, de maio a } \\
\text { agosto); } \\
\text {-Cultura do cafezinho e da hospitali- } \\
\text { dade; } \\
\text {-Sobreposição da vida urbana e rural. }\end{array}$ \\
\hline Meio produtivo & $\begin{array}{l}\text { - Clima equatorial, chuvas dis- } \\
\text { tribuídas durante todo o ano, } \\
\text { relevo montanhoso; } \\
\text {-Principal região produtora } \\
\text { caracterizada como cidade- } \\
\text { região: um aglomerado poli- } \\
\text { cêntrico de cidades que com- } \\
\text { partilha nivel semelhante de } \\
\text { desenvolvimento, forte rela- } \\
\text { ção urbano-rural e dependên- } \\
\text { cia econômica da cultura do } \\
\text { café; } \\
\text { - Localização estratégica da } \\
\text { principal região produtora, } \\
\text { equidistante dos três princi- } \\
\text { pais centros urbanos; } \\
\text {-Paisagem natural e cultural } \\
\text { rica, diversa, atrativa para o } \\
\text { turismo. }\end{array}$ & $\begin{array}{l}\text { - Clima tropical, propício para o cultivo } \\
\text { do café, com distribuição de chuvas } \\
\text { adequada, relevo montanhoso na } \\
\text { maior região produtora (Sul de Mi- } \\
\text { nas); } \\
\text {-Principal região produtora em locali- } \\
\text { zação estratégica no centro do país, } \\
\text { equidistante de três dos principais } \\
\text { centros urbanos e turísticos (São } \\
\text { Paulo, Rio de Janeiro e Belo Horizon- } \\
\text { te); } \\
\text {-Paisagem natural e cultural rica, di- } \\
\text { versa, atrativa para o turismo. }\end{array}$ \\
\hline
\end{tabular}


Um produto turístico inovador e que inclusive foi utilizado como objeto de estudo em publicações relacionadas às "novas ruralidades" e à concepção de produtos turísticogastronômicos (TORGA, 2011; ANDRADE, 2010) é a Rota do Café Especial, situada na cidade de Carmo de Minas, no Sul de Minas Gerais. O produto segue em funcionamento desde 2008, sob a gestão do Grupo Sertão, que é composto por tradicionais cafeicultores sul-mineiros. Estes, há mais de 100 anos, produzem cafés de excelente qualidade e são reconhecidos mundialmente. A rota é gerida por um turismólogo, em um formato aproximado ao modelo Recuca, porém sem o envolvimento direto dos visitantes no processo produtivo, o que reduz a riqueza da experiência.

De qualquer maneira, observa-se que nem o caso estudado por Torga (2011) e Andrade (2010) apresenta envolvimento da cafeicultura familiar, sendo a experiência turística manejada, de certa forma, à margem do processo produtivo. O produto também parece estar desprendido do território em seu entorno, na medida em que pouco ou nada envolve a complementação do produto por atividades desenvolvidas em outras propriedades.

Um desafio à implantação de um turismo rural que envolva o visitante nas atividades da cafeicultura familiar encontra-se na sazonalidade do ciclo produtivo do café. Ao contrário do que acontece na Colômbia, existe uma concentração na necessidade de mão -de-obra durante o período de maio a agosto, o que dificulta a atenção ao turismo nesse período. Por outro lado, exatamente nessa etapa é possível observar e viver toda a cadeia do café, sendo o mais atrativo para o turismo rural na agricultura familiar. Dessa forma, carece-se de soluções que permitam ocupar o tempo do visitante fora dos períodos de colheita, para preencher o tempo ocioso da mão-de-obra familiar e gerar fontes alternativas de renda. Uma possibilidade é a inclusão de outros gêneros, como a preparação de doces, queijo e cachaça, uso de culturas consorciadas ao café que tenham apelo atrativo, festas e manifestações culturais, entre outras atividades distribuídas entre propriedades rurais e também nas sedes dos municípios que abrigam a cafeicultura. Outra possibilidade é a inclusão de outras etapas da cadeia do café dentro das propriedades produtoras, como a classificação e degustação, torrefação e preparo, que podem ser realizadas em qualquer época do ano. Devido ao alto custo de implantação, as estruturas necessárias podem ser construídas comunitariamente ou divididas em etapas, em diversas propriedades.

Para melhor entendimento, busca-se apresentar a seguinte orientação dos componentes de um roteiro ideal para o turismo focado no café:

\section{Equipamentos e serviços:}

- Alojamento: em meio de hospedagem rural, no qual seja desenvolvida uma atividade produtiva, preferencialmente, a cafeicultura;

- Restauração: refeições típicas da região, preparadas com produtos locais e desfrutadas em ambiente tradicional, celebrando o hábito de partilhar o momento da refeição como momento de encontro com o outro.

Atrações e atividades (acompanhamento e participação):

- Plantio, seleção de cultivares e preparo do solo; 
- Manejo das lavouras (adubação, poda, condução)

- Colheita manual ou mecanizada

- Pós-colheita, secagem e beneficiamento

- Armazenamento e seleção de amostras

- Análise da qualidade dos grãos - prova de xícara (apresentação do trabalho do Degustador)

- Processo de torração e moagem artesanal, semi-industrial ou industrial

- Preparo de café coado tradicional

- Preparo de café espresso e outros métodos de preparo (apresentação do trabalho do Barista)

- Gastronomia com café (preparo de produtos à base de café, como bebidas, pratos doces e salgados)

- Subprodutos da cafeicultura (móveis de madeira de café, cosméticos, artesanato, entre outros)

Além das atividades supracitadas, que objetivam a vivência completa da cafeicultura pelo turista, incentiva-se o incremento da experiência por atividades relacionadas a outros gêneros do agronegócio, participação em eventos, festas e manifestações religiosas, folclóricas e culturais em geral, como mecanismos para maior atratividade do turista.

Para o tripé que sustenta o modelo colombiano, é notável a existência de símbolos marcantes para cada esfera. Assim, tem-se:

- Produto (Café) - “Cafés suaves”

- Produtor (Cafeicultor) - "Juan Valdéz"

- Meio produtivo (microclima) - "Visite a Colômbia: o risco é que você queira ficar" (slogan promovido pela Proexport Colombia, agência oficial de promoção de turismo, investimento e exportações, que refuta a imagem de país perigoso e promove as atratividades do país).

Considera-se necessário que o estado de Minas Gerais desenvolva e adote uma marca gastronômica que inclua o café, associando-o ao modo de vida local, à hospitalidade do mineiro, características que já são conhecidas nacional e internacionalmente. A imagem de Minas está atrelada ao bem-comer e ao bem-receber, que precisam ser veiculados com o objetivo de valorizar os produtos de importância regional, agregando valor na venda dos mesmos e gerando fontes alternativas de renda para o produtor familiar. Em outra via, a agricultura familiar precisa ser capacitada para adaptar suas propriedades e atender adequadamente ao turista, o que deve prioritariamente ser realizado por organismos de extensão rural. Tal capacitação apresenta-se ainda mais urgente quando se leva em conta a proximidade da maior região produtora brasileira, o Sul de Minas, das três principais cidades-sede que receberão jogos da Copa de 2014, e portanto distribuirão um enorme fluxo turístico, em proporções ainda não quantificáveis. 


\section{Considerações Finais}

Perante as observações realizadas, considera-se possível e necessária a adoção de um modelo de aproveitamento turístico focado na cafeicultura familiar. O tripé produto x produtor x meio produtivo mostra-se altamente aplicável ao caso do café em Minas Gerais, demonstrando que as ações devem ser realizadas em duas vias: a consolidação do estado de Minas enquanto destino por uma identidade gastronômica que inclua o café, e a capacitação de cafeicultores familiares para a adequação de suas atividades ao recebimento de fluxo turístico.

Para lograr tais objetivos, entende-se que a parceria entre governos locais e instituições de ensino e capacitação seja adequada, bem como o trabalho conjunto do governo do Estado de Minas Gerais, via Secretarias de Turismo e de Agricultura, Pecuária e Abastecimento, com os Ministérios do Turismo e do Desenvolvimento Agrário. O diferencial que levou a Colômbia à atual projeção mundial foi a constituição de uma federação coesa e centralizadora em sua atuação para o cafeicultor familiar. Essa não é a realidade mineira, que se distribui em cooperativas que nem sempre constituem a melhor opção de comércio para o cafeicultor. Portanto, espera-se que tal passo unificante tenha a chancela do governo do Estado e seja estimulado pelos organismos de extensão rural e pesquisa no campo.

\footnotetext{
Notas

${ }^{1}$ Derriça: método de colheita manual na qual todos os frutos do café são arrancados de uma só vem, independente do grau de maturação.

${ }^{2}$ Via úmida: método de beneficiamento do café no qual o grão é descascado antes de ser levado ao terreiro de secagem, para reduzir o risco de fermentação em locais de alta umidade. O resultado desse método é o café cereja descascado, mais leve e de acidez característica.

${ }^{3}$ Café natural: café produzido por via seca, no qual a secagem acontece com a casca do fruto. $\mathrm{O}$ resultado é um café mais encorpado e doce, entretanto se a secagem é inadequada, pode-se obter a bebida "riada", ou fermentada e de baixa qualidade

${ }^{4} \mathrm{O}$ presente artigo foi um desdobramento da experiência vivenciada no Eixo Cafeteiro da Colômbia, em 2011, promovida pelo Projeto Umami, que tem por finalidade associar a atividade turística ao café de origem e à cultura cafeeira. Disponível em: http://www.projetoumami.blogspot.com.br/
}

\section{Referências bibliográficas}

ANDRADE, H. C. C.; O café especial como produto turístico gastronômico: reflexões sobre o café especial e suas interfaces com o turismo. Monografia. Belo Horizonte: UFMG, 2010.

ARANGO, O.; Ciudad-región Eje Cafetero: hacia um desarrollo urbano sostenible. Desafios, Bogotá (Colômbia) (12): 109-130, semestre I de 2005.

BRASIL. Panorama do Turismo Rural na Agricultura Familiar./ Ministério do Turismo e Ministério do Desenvolvimento Agrário (cooperação técnica) - Brasília: Ministério do Turismo, 2007. 
BRASIL. Ministério do Turismo. Turismo rural: orientações básicas. / Ministério do Turismo, Secretaria Nacional de Políticas de Turismo, Departamento de Estruturação, Articulação e Ordenamento Turístico, Coordenação Geral de Segmentação. - 2.ed - Brasília: Ministério do Turismo, 2010.

BRASIL. Presidência da República. Estabelece as diretrizes para a formulação da Política Nacional da Agricultura Familiar e Empreendimentos Familiares Rurais. Subchefia para Assuntos Jurídicos da Casa Civil. 2006. Consultado em 28/05/2012. Dispobnível em <http://www.planalto.gov.br/ccivil_03/_ato2004-2006/2006/lei/l11326.htm>

COELHO, F. M. G.; O café num outro retrato do Brasil rural: o lugar da agricultura familiar. In: Informe Agropecuário, Belo Horizonte, v. 26. Edição Especial. EPAMIG, 2005.

CORDEIRO, A. T. et al. Características da propriedade cafeeira, do cafeicultor e do parque cafeeiro. In: VILELA, P. S.; RUFINO, J. L. S. (coordenadores); Caracterização da Cafeicultura de Montanha de Minas Gerais. Belo Horizonte: INAES, 2010.

DONZELES, S. M. L. [et al.]; Técnicas para o processamento de café e inovações tecnológicas acessíveis para a produção de café com qualidade. Boletim Técnico 87 . Viçosa: EPAMIG, 2008.

FLEURY, M. T. L.; Juan Valdéz, a estratégia por trás da marca. Gazeta Mercantil, Caderno A, pag. 3. Publicado em 23 de junho de 2008. Disponível em:

http://www.erudito.fea.usp.br/portalfea/Repositorio/523/Documentos/Juan\%20Valdez,\% 20a\%20estrategia\%20por\%20tras\%20da\%20marca\%20(23.06.08).pdf

IBGE. Agricultura Familiar: Primeiros Resultados. Censo Agropecuário 2006. Consultado em 28/05/2012. Disponível em:

http://www.fao.org/fileadmin/templates/ess/ess test folder/World Census Agriculture/ Country info 2010/Reports/BRA BRA REP 2006.pdf

PEDINI, S.; Certificação e comercialização de cafés da agricultura familiar. In: Informe Agropecuário, Belo Horizonte, v. 26. Edição Especial. EPAMIG, 2005.

SCHLUTER, R. G.; Gastronomia e turismo. São Paulo: Aleph, 2003.

SCHOLER, M.; Coffee production. Copyright by SASI group (Sheffield) and Mark Newman (Michigan): 2006.

TORGA, P. A. A.; Novas ruralidades e a Rota do Café Especial, no município de Carmo de Minas. Monografia. Conselheiro Lafaiete: UFMG, 2011.

TORRES, I. A.; Café com o outro: o café mineiro como lócus de encontro entre visitante e visitado. Monografia. Belo Horizonte: UFMG, 2010. <http://www.cafedecolombia.com/>; Acesso em 28/05/12.

<http://paisajeculturalcafetero.org.co/contenido/descripcion>; Acesso em 28/05/12.

<http://www.federaciondecafeteros.org/>; Acesso em 28/05/12.

< http://www.recuca.com/en/home.htm>; Acesso em 28/05/12. 
Helga Cristina Carvalho Andrade: Instituto Federal de Educação, Ciência e Tecnologia Sul de Minas, Pouso Alegre, MG, Brasil.

Email: helgadeandrade@hotmail.com

Link para o currículo Lattes: http://lattes.cnpq.br/0480370402754934

Marina Carneiro Bernardes Moss:Universidade Federal de Minas Gerais, Belo Horizonte, MG, Brasil.

Email:marinamoss@yahoo.com.br

Link para o currículo Lattes: http://lattes.cnpq.br/5661707135512735

Data de submissão: 30 de maio de 2012

Data de recebimento de correções: 17 de agosto de 2012

Data do aceite: 17 de agosto de 2012

Avaliado anonimamente 